\title{
Early Development of News Sites in the United Kingdom and the United States in the 1990s: Exploring Trans-Atlantic Connections
}

\begin{abstract}
The many close, trans-Atlantic connections between the United States and Britain were the setting and inspiration for much of how these nations' respective media systems produce and consume news online today. Publishers, software engineers and journalists in both nations shared worries about the impact of the internet on the newspaper industry, and the early migration - or, in many cases, the uneven migration-to online news sites during the 1990s. This paper will explore some of those shared concerns, down to the editor and reporter level, with a special focus on the mid-to-late 1990s, and concluding with what changed by the end of that decade, and what did not. It is part of a larger study examining the internet and journalism's initial encounters. It is based on a close reading of trade publications, memoirs, oral-history interviews and other primary-source material, and inspired by the work of Niels Brügger, with its treatment of 'web history' in a serious and contextualized way.
\end{abstract}

\section{Keywords}

internet history, media history, history of online news, transnational media history

In 2021, looking back at how journalism looked online in the 1990s, with its slow, buzzing dial up, simplistic graphics made of low-resolution photos (if they were posted at all) and lack of streaming, it might be hard to see the connection to the present, with its TikTok, immersive apps and omnipresent (more or less) Wi-Fi.

And yet, we can still learn a great deal about how online news-as we know it-came to be, starting 25 years ago. Comments, links, home pages, and dynamic news reporting via online audio, and even video, most definitely did exist then online on newspaper sites, and would, in time, expand into 
what we consumed, medium-agnostic, on our smartphones, tablets and other devices. As with any technology, online news was path-dependent, and in this case, particularly cross-national, in this case between the United Kingdom and the United States. ${ }^{1}$ Transnational, comparative work, especially with media or journalism history, adds important context to national histories of technologies, showing that they are, in fact, embedded in global networks and information flows, but also quite literally connected via infrastructures that include physical transmission (i.e. undersea cables) shipping, mining (for the rare-earth metals used for computer components), programming, and data storage in the form of server farms.

In May 2001, Ruth Addicott, writing in The Press Gazette in the United Kingdom, observed that 'magazine publishers are beginning to breathe again after years of panic, intimidation and misinformation caused by the impact of the internet.'2 Addicott was paraphrasing an American business leader at a recent meeting of the British Professional Publishers Association, a prominent trade organisation for magazines. These kinds of interactions were relatively commonplace, as has been explored by other scholars. ${ }^{3}$

But this summary of a speech about 'the hype of the web' is revealing of the many close, stillunderexplored, trans-Atlantic connections between the United States and Britain. Publishers, software engineers and journalists in both nations shared worries about the impact of the internet on the newspaper industry, and the early migration-or, in many cases, the uneven migration-to online news sites during the 1990s. This study will explore some of those shared concerns, down to the editor and reporter level, with a special focus on the mid-to-late 1990s, and concluding with what changed by the end of that decade, and what did not. By focusing on the exchange and shared struggle of the United States and Great Britain, scholars can better understand the ways both nations' journalism industries reacted to, adopted or failed to adopt to the internet. One of its chief aims to help debunk the myth that the world of newspapers was somehow obliterated by simplistic, bad choices, including failing to charge for content or in putting its best journalism online. Some of this narrative is grounded in reality, of course, including the loss of classified advertising, the 'original sin' of giving away content for free without paying for it, and not embracing mobile devices fast enough, among other supposedly decisive, causal factors. ${ }^{4}$ But the larger story is a more nuanced one, with many possible 'could-have-beens,' to be explored below.

In the United States and the United Kingdom, there was early enthusiasm in the respective journalism trade press, but also in more academic circles, about what 'going on-line' (in the parlance 
of the day, the hyphen was often included) promised, and it was mostly good. While there was some concern about the long-term impact on profit margins, most of the stories written by reporters and editors focused on early adopters, experimental methods of online storytelling, and future plans to bring more computer-assisted reporting (CAR) methods to the online space, among other hopeful trends.

By the end of the decade, with the dot-com bubble bursting and the dawn of the 2000s, more scepticism and pronounced concern would creep into narratives about technology and what it was doing and would do to journalism. But in order to better understand our digitally delivered journalism today, it helps to see the long, 30-year arc of development that came before. The 1990s, with its heady mix of both traditional momentum and change, transition and lingering stability from the industrial journalism of the late twentieth century, is worthy of special consideration. A strong comparative element between the United States and United Kingdom will help to draw out both similarities and differences, and paths not taken in both countries. These included more aggressive efforts to develop internet-based journalism, integrate early online sites better with larger print operations, and embed news workers writing for these sites into more traditional newsroom spaces, instead of isolating them.

It is also important to reject teleological, simplistic histories of communication technology (especially a technology such as the internet, composed of numerous other technologies), and to show the complexities of a moment such as that experienced by journalism organisations in the early-to-mid 1990s. At this point, even intelligent, thoughtful people were uncertain as to the next step in the face of disruption and change. An empathetic, cross-national (comparing two countries) media history such as what follows shows that no one country, including and especially the United States, exists apart from the rest of the world, and that branching paths and discourse about them show a messy, unclear future, not a foreordained, single path. The history of the creation of a commercialized internet, and how news organisations adopted to its possibilities (or not) needs more connected, global accounts, and not just those focused on the United States. By looking at how discourse about early sites was mutually shaping on both sides of the Atlantic, this article can make a modest nuanced intervention into received histories of the internet and newspapers, by showing how small, constitutive choices added up, gradually and often in unseen ways, to become the more inevitable-seeming, path-dependent decisions that seem clear in retrospect but which were anything but clear in the moment. 


\section{Context: newsroom computerization right before the internet}

When Paul Williams wrote his conclusion to The Computerized Newspaper in the United Kingdom, in 1990, he contemplated what a transition to micro-computers, or personal computers, would mean for journalists in the 1990s. This would be defined by the 'fourth wave' of newsroom computerization: 'the use of 'standard platforms'-computers (...) that you can buy off the shelf' alongside software systems that you could also buy as-is. This was in contrast to the customised, multi-million dollar/ pound installations by the likes of Raytheon or Digital Equipment Corporation, Systems Integrators Incorporated (SII), Atex, or Hastech, in the United Kingdom, specifically. ${ }^{5}$ Williams talked about how PCs were becoming the norm in the US, but how there were some differences in the United Kingdom. These differences, which are discussed below, show how, despite many cultural and technological parallels, the immediate pre-internet era was experienced differently by newsrooms in Britain than in the United States.

In Britain, the main daily paper was likely to be the national or at least regional paper of record (the leading so-called 'quality’ paper, in the language of British journalism), due to a variety of factors, including the size of the country but also the politicised presence of party-affiliated news. Small papers in Britain were likely truly local-i.e. they could 'only dream of the sort of investment that their American cousins can afford, so the introduction of new technology for them must be at a much lower cost.' In other words, American newspapers and their owners could afford more readily the expenses required to upgrade their newsrooms and news workers with the latest technology tools. Also, in contrast, in the US, local newspapers were much more distributed, and that also meant that they were more interested in many cases in investing in technology for their workers, individually or as part of chains. ${ }^{6}$ Stories from the trade press in the 1980s were replete with tales of cost-effective newsroom computer retrofits.

While the history of newsroom computerization, pre-civilian internet, is worthy of its own story, there were some significant overlaps with pre-internet networks, including legal and other research databases, that also distinguished the similar but somewhat divergent paths both nations' newspaper industries took when it came to the development of early news sites. ${ }^{7}$ These sites emerged out of an existing computing and network environment that influenced discussion about them, and their eventual design. Whether it was through American Online, Prodigy, CompuServe or their emulators in their pioneering use of graphical-user interface (GUI) technologies, newspaper sites 
were rarely built from scratch and instead constructed as part of larger efforts by other companies, with that process being worthy of its own study.

When Williams, for example, notes that few, if any, newspapers had been able to truly move over to an all-PC system, for layout, pagination and text input, he was speaking primarily of the smaller papers in the United Kingdom that struggled to save enough money to adopt such systems. And yet, when he discusses the use of early portable modems, or 'phone couplers', to transmit early digital images from reporters in the field back to their newsrooms, he could be describing developments in the States. Ultimately, the dream of publishers and owners on both sides of the ocean was similar: 'the aim must be to produce one work station that can do the lot, and be integrated with existing databases, maintaining the integrity both of the stories and of the composition.' To be clear, at the time, with the possible exception of some customized Apple Macintosh computers, this was still a few years away. ${ }^{8}$

In the British context, there was a long tradition of relying on mainframes or large minicomputers instead of PCs, despite the gradual adoption of IBM machines starting in the 1970s and 1980s. This is explored in detail in Mar Hicks' history of the British computing industry during the Cold War. ${ }^{9}$ In the US, there was greater emphasis on decentralised systems, including in how workers were hired and trained. ${ }^{10}$

There were attempts-mostly unsuccessful, to emulate the British Prestel videotex system, developed by the Post Office there, and the French Minitel. ${ }^{11}$ In the US, this primarily involved the multi-million-dollar Viewtron project by Knight Ridder, which tried-and failed, to recoup a $\$ 55$ million investment in a pre-internet information service for average Americans. ${ }^{12}$ Other systems, such as the Fort Worth, Texas, Star-Telegram 'Startext,' were more successful, on a local and regional level. This study does not explore these related technologies, but the work of other scholars, such as Kevin Driscoll, does. ${ }^{13}$ For our purposes we will focus on the era from about 1993 through 2001, with a particular emphasis on circa 1995 to about 2000. This was a moment of possibility and change, with long-term consequences for the newspaper industry. Indeed, decisions made then-and not just about the use of paywalls and customized editions online, etc.-continue to reverberate down to our present moment, some now-thirty years later. By examining this period as a media-historical hinge point, especially in a comparative way, we can understand more of the difficulties of prediction and why proactive responses to disruptive innovation are so challenging. ${ }^{14}$ 


\section{Theoretical influences}

Following Valerie Belair-Gagnon and Allison Steinke and their summary of innovation-oriented research in journalism studies, this project is grounded in several theoretical approaches. ${ }^{15}$ The first is the older but still useful diffusion-of-innovations, popularised in the mid-twentieth century by historians of technology but especially shaped by Everett Rogers. Eric Schatzberg has outlined a history of the larger debates, including criticisms, around Rogers' influential Diffusions of Innovations, published in 1962. ${ }^{16}$ This much-discussed theory of technology adoption has an enduring quality, speaking as it does to innovators, early adopters, early majority, late majority and laggards, as 'adopter categories.' In the classical conception of Rogers' theory, a further five 'factors' impact how innovations are adopted, including relative advantage, compatibility, complexity, triability, and observability. ${ }^{17}$ It has been criticized for being too linear, not comprehensive and too focused on corporate concerns, versus innovation by amateurs and hobbyists. ${ }^{18}$

In this study, I am particularly influenced by how the Spanish media historian Ángel Arrese, in his study of the origin of paywalls, has used this approach, and elaborated on the 'retro-innovation' that accompanies discourse about innovation by industry practitioners. This is the process by which past choices are justified through the lens of the present. One could think of it as the 'oh, of course that was how things were supposed to happen,' argument, which, while greatly simplified, is essentially a presentist perspective that looks at technologies as received versus evolving, or as steady state, as opposed to more fluid. ${ }^{19}$ In adopting the latter approach, Arrese is focused on what he describes as the 'return to basics of rediscovery of the value of news,' in regards to paywalls and subscription models for journalism, within but also without the American context. He examines how the rhetorical and literal (at least in the digital realm) construction of paywalls for the leading publications in France, Spain, Germany, the United Kingdom and other European countries, as well as select parts of East Asia, coincided with a move to rebuild the ramparts, so to speak, in the United States. ${ }^{20}$ He applies Rogers' diffusions theory, which helps to explain how a practice once held as anathema-charging again for access to news, or at least premium news content-was re-adopted and re-valued.

When reading discourse from the 1990s, one can quickly note that the newspaper industry was not caught in some kind of simplistic flat-footedness, or doomed to one direction, and so the diffusions model, while helpful, is not a panacea. While the narratives of adoption, acceptance, 
rejection, setback and success roughly follow the steps outlined by Rogers, there are some critical divergences. The impact of the internet on the newspaper industry and in particular the ways that British and American leading newspapers developed their sites elides, or even resists, an easy explanatory model (not to say that the more evolved version of the diffusion of innovations, focused on a holistic or systems approach, is not sophisticated). In this approach my work is also influenced by Steen Steensen's call for a grounded theory of innovation focused on the power of individual actors within institutions (while also not reducing media-history narratives to great-men-andwomen tales). ${ }^{21}$ Steensen draws on Pablo Boczkowski, who identified three structural factors, including proximity between print and online newsrooms, gatekeeping reproduction, and a view of the audience as consumers or producers.

But he also identifies a fourth factor, namely, the suitability of a technology (or, rather, how 'is it suited to fulfil its promise'). ${ }^{22}$ Suitability has a slightly esoteric feel, but a respect for users' needs and a practical element are built into this concept, including an awareness of the limitations of certain platforms. In the case of the promise of the internet in opening access to newsrooms for readers, for curating stories that were more interactive and substantive, and not just as adjunct or supplemental, this study takes up this concern raised by Steensen, and responds to his call for applications for grounded theories of innovation. Steensen found in his study of a Norwegian news site that individual actions and cooperation still mattered, and that the multiple, overlapping processes of innovation can be 'complex and random due to the unstable structure of online newsrooms.' He called on future researchers to contemplate the impact of newsroom autonomy, work culture, management, the relevance (and not just the existence) of new technology tools, and of course those innovative, individual actors. ${ }^{23}$ This study attempts to do just that, looking closely at trans-Atlantic connections and influences.

\section{Methods and scope}

When thinking about how to approach the study of the recent history of communication technologies, especially those located largely online, we should reflect on the contingency and fragility of these sources. Many sites, software programs and even hardware from this era have become either inaccessible or have simply vanished. Some remain, thanks to the diligent work of web archivists. In this regard, this project is influenced by the important work of Megan Sapnar Ankerson and Jessa 
Lingel, with their focus on 'web 1.0' technologies, specifically early website design and the role of e-commerce on Craigslist. ${ }^{24}$ It is also influenced by Niels Brügger and Ian Milligan, with their concern for the challenges of media-history research on the ersatz web, with all its disparities and missing links (literally). Both have conceptualised 'web history' as a distinct subfield of historical inquiry, and their admonition to think of layers and linkages, and to seriously consider the 1990s and 2000s as truly now part of history, and not 'just' the present, are critical for this kind of project. ${ }^{25}$

As part of a larger study, approximately eighty issues of Columbia Journalism Review, the Society of Professional Journalists' Quill, Editor \& Publisher, and the UK-based Press Gazette were analysed for stories and photos about early online news efforts, with a special focus on coverage and discussions about and around online news sites. While the researcher was able to locate a number of issues from the early 2000s of the Press Gazette via the publication's online archive, and has access to some issues from the 1980s and 1990s, he will need to visit the physical holdings of institutions later for more access. The global pandemic of 2020-2021 limited the ability to visit these places in person and necessitated a reliance on correspondence and digital archives, including memoirs. ${ }^{26}$ In the meantime, using the other primary-source material mentioned here, including interviews, the researcher was able to get a good sense of the British news-site scene for the period in question. The inclusion of c. 2001-2010 Gazette issues also contained a number of retrospectives or reviews of previous, 'firsts' for British journalism moving online during the 1990s. While the focus was on the late 1990s, then, reading into the 2000s provided further, critical context. This effort included about twenty issues total with as many as three to five stories in each issue, for about eighty individual news items examined, with a smaller subset of about 20-30 stories read more closely. This closer examination involved a comparative rereading (reading similar articles from the other trade publications again), and notetaking. The year ranges included c. 1991-1995, then c. 2000-2002, then a smaller number from c. 2004-2007. As far as possible, the American and British trade journals analysed were compared across these year ranges, to track developments and key moments in a holistic pattern, before, during and immediately after the move to more online news. ${ }^{27}$ It should also be noted that this study did examine newspaper sites from this era, including for 'quality' and tabloid papers, but with a focus on the former.

In addition to the above, additional contemporary sources were consulted, included textbooks, reports, memoirs and scholarly studies from the 1990s and early 2000s, to provide greater context on the era. These included Roger Fiddler's (Knight Ridder's innovation lab director) self-published 
memoir, Touching the Future, along with Jim Hall's Online News, published in the United Kingdom in 2001. A particular effort was made, due to the trans-Atlantic nature of the study, to locate and analyse first-person accounts by British journalists and media managers. With American new workers, due to the preponderance of material from the US, while these were included with the study, as far as possible, British first-person sources were privileged. The Internet Archive's primary-source resources were also consulted, including the Wayback Machine (with some examples included here), to see what these sites looked like visually, when feasible. To supplement the above, the researcher interviewed the editor of a popular textbook on web-based journalism in the late 1990s, a retired Knight-Ridder executive who helped to oversee online implementation, and a British journalist who worked during this period, about their perspectives on this era, along with a scholar whose career had significant professional crossover in the United Kingdom journalism scene in the 1990s. In the latter case, to be clear, this was done in order to reinforce the lack of access to trade publications from the United Kingdom during the time period examined. ${ }^{28}$

Taken together, these sources-trade publications, contemporary material and oral-history interviews - constitute a powerful triangulation of evidence on an era that often falls into an analogueto-digital interregnum. ${ }^{29}$ It is can be surprisingly difficult to locate online material that is not just static from this era, and as it is still well within living memories for many of the participants, the challenges of 'near history' are present, including contestation of events, and the uncertain outcomes of certain software and hardware tools. By examining several different kinds of sources, the researcher was able to identify important early trends and some paths-not-taken, which will be explored below.

\section{News websites in the United Kingdom in the mid-1990s}

When looking at how 'home' pages for newspapers were conceived of, created and used in the mid1990s in Britain and the United States, it will help to briefly trace the ways these sites appeared in both countries. In his 2001 book on the news industry and the internet, British scholar Jim Hall noted that journalism was just the third major global sector, after the military and higher education, to go online. By the late 1990s, both the United States and Great Britain had most of their major national papers on the internet in some way, shape or form. ${ }^{30}$

In fact, from 1995 to June 1997, the number of newspapers online grew from as many as 491 to 3,600, with many of these found in either the United States or the United Kingdom. ${ }^{31}$ Other, more 
conservative estimates put that figure at growing from 50 in 1995 to 5,000 in 1999, with 2,800 in the United States. ${ }^{32}$ But numbers alone do not tell the full story. The appearance, purpose and actual use of these sites needs to be understood in their proper context, along with the motives of those who built them. What follows, then, is not meant to be exhaustive, but is, rather, a brief, historically grounded examination of some of the major trends during the mid-to-late 1990s for news organisations and their moves online. It should be understood at the beginning that 'news site' here usually refers to the home pages of newspapers, but also a few (then rare) dedicated online-news operations and their sites.

In Britain, The Guardian, The Times, The Telegraph and BBC News were all leaders when it came to getting their journalism online, with the first former under the banner of 'Guardian Unlimited'. Alan Rusbridger, the editor-in-chief of The Guardian for some 20 years beginning in 1995, recounts in his memoir that 'reach before revenue' was the dominant model then, for how to develop an online presence, and he honestly recalls, too, the many missteps and accidents along the way. On a factfinding mission, right before his tenure as the top editor, he visited his American counterparts, seeing first-hand the early efforts being made by The New York Times, The Atlanta Journal-Constitution (with its alliance with the Prodigy online service), the Knight Ridder laboratory in Boulder, Colorado, run by Roger Fidler, with his ahead-of-their-time, mock-up news tablets, and the Chicago Tribune, among other destinations. But this was no mere sightseeing tour. It was part of a long tradition of technology and idea exchange between journalism on both sides of the Atlantic.

In the more immediate sense, though, the trip made an uncertain impression on Rusbridger. Despite his status as an early adopter and even, later, an early majority leader, to borrow again from Rogers' theoretical framework, and Arrese and Steensen's emphasis on individual choices, it is clear that Rusbridger was unclear about what to do at a critical point. Looking back from a quarter century, he is right to point out that no one, not even 'navigators and pioneers' like Fidler (in other words, innovators), really knew what was going to happen next. There was simply a vague sense that 'it would be more reckless not to experiment,' and that big and small publishers alike were conflicted on how to proceed with transitioning online, how fast, and when. ${ }^{33}$

By March 1996, The Guardian began to plan its more intentional online launch in earnest, deciding not to charge for its online content, on the presumption that more contact with readers would help advertising and eventually the print product. Even so, the initial amount of money invested was $£ 200,000$, a modest sum compared to the $£ 6$ million being invested into The Guardian’s 


\section{Guardian Unlimited}

\section{beinformed

The Guardian The Observer



Please note that you have to register for our sites once you go past the homepage. This should only take a couple of minutes and will allow you permanent, free access to all our sites.

Register now *

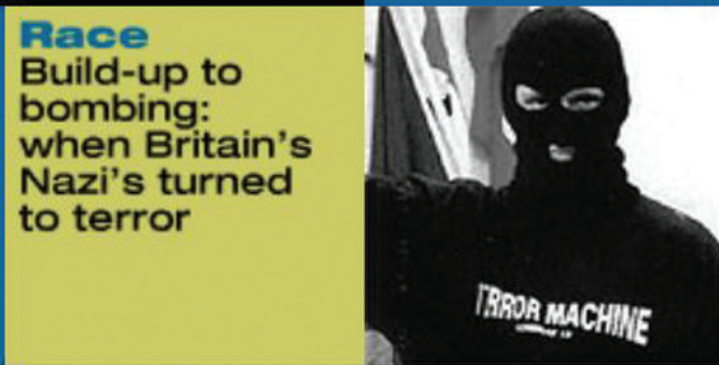

Network sites

News | Football | Cricket | Film | Work | Jobs

\section{Special sites}

Millennium | The Word | Flat Eric

Competition I Virtual Monet | Notes \& Queries

\section{The Guardian}

Front page | Media | Education | Society | Online | Friday Review | Weekend

\section{The Observer}

Front page | Business | Review | Life |

Figure 1. The Guardian Unlimited, circa April 1999. This was a dedicated news site run by The Guardian that in many ways imitated the success of the San Jose Mercury News and its Mercury Center from the same era. Source: Internet Archive, Wayback Machine. 
sister paper, The Observer, over three years. ${ }^{34}$ This plan would be revised again in 1997, with limited forays online before that, by the paper, during major news events such as the death of Princess Diana on August 31, 1997. In July 1998, six sites, with an additional twelve over the next year and a half, under the broad umbrella of 'Guardian Unlimited,' brought in an initial 100,000 registered readers (often described as 'users'). The 'verticals' run by The Guardian's new digital team focused on breaking news, politics, film, sports, books, arts and jobs.

Like other sites during this era, it was mostly text-based, with some lower-resolution images, but was pioneering in its use of permanent URLs, forums, and digital photography. Streaming video, which would not emerge until the mid-2000s, was not present. While some video files were included, they took at least several minutes to download and play, and often much longer. But by October 1999, there were some 500,000 registered users, with about sixty news workers, twenty of them being more traditional journalists, dedicated to the site. ${ }^{35}$ While it was, in time, quite successful, especially as American readers discovered the site in the wake of 9/11, lingering tensions were present. An academic team looking at the paper in 1998 reported that only a minority of reporters were using the web on a daily basis. Indeed, it took several years for everyone in the main newsroom to gain full access to terminals that let them get online in a more functional way. These were added to the newsroom at a cost of some $£ 3.5$ million. ${ }^{36}$

Eventually, under first Ian Katz and then Simon Waldman and Emily Bell, Guardian staffers signalled out by Rusbridger as important to the success of the site, over the course of its first five years of existence, some $£ 18$ million would be spent, with staff costs being among the chief expenditures. While this seems like a great deal of money, Rupert Murdoch would spend some $\$ 2$ billion on various online efforts, in contrast, most of which failed spectacularly, from 1999-2001. ${ }^{37}$ Projections of how much money could be made at the more careful Guardian ranged from $£ 8-30$ million a year in profits, by 2005 , but that was still very much unclear, something that worried Rusbridger in the midst of the dot-com bubble in the summer of $2000 .^{38}$

Peter Preston, the former editor-in-chief of The Guardian before Rusbridger, who had been helping lead the technology development at The Guardian as part of its Product Development Unit, expressed his own scepticism as late as 2007, at newspaper conference in the United Kingdom. When asked by a colleague about the topic, he said that 
he did post work online but never accepted any payment for that work because in his view it did not constitute real journalism. It was shovelware. Overly long, insufficiently well[-]edited, first[-]draft materials. He was not alone in holding these views [sic]. ${ }^{39}$

Shovelware, to be clear, was a derogatory term for content posted to the web. ${ }^{40}$ While the paper had an additional financial runway, due to its unique ownership model (via The Scott Trust, still supplemented today by donations from readers), the doubt expressed by Preston and others was not necessarily misplaced. Through the early 2000s, it was not clear if websites, and later a social-media presence, would be as necessary as they seem today for news organisations. They were decidedly still newspapers, at this point.

Elsewhere in the United Kingdom, the launch of BBC News Online in November 1997, was met with initial scepticism, as it was perceived to be 'late on the scene, arriving long after both British and international competitors had established their online presence.' ${ }^{41}$ However, in time, with an investment of some $£ 20$ million, BBC News was able to give its forty dedicated digital journalists the margin they needed to succeed. Relying on its global network of some 2,000 staff, 250 correspondents, along with 13 domestic and 42 international bureaus, it was soon a respected success. Daily video and hourly audio versions (the latter also in Arabic, Cantonese, Mandarin, German, Russian and Spanish) of the BBC World Service were popular, especially as leadership opted for less flashy, more robust tools such as RealVideo and RealAudio. It had one million hits on its first day of operation, and more than eight million-page impressions a month by March 1998. By June 1998, BBC News had 61,000 individual pages of news content. ${ }^{42}$

The BBC had the advantage of tapping into a deep bench and planetary network, and, of course, was subsidized by a TV licensing fee and an exclusive lock on its customers. It was also, obviously, not a newspaper and thus did not have to grapple with infrastructure concerns to quite the same degree. For example, while many newspapers had to hire temporary stringers to cover events in the developing world, the BBC would often have a fully staffed news bureau on hand. Nonetheless, like The Guardian, the BBC demonstrated an early appetite for trusted news by legacy institutions, despite the popularity of sites such as The Drudge Report in both the United States and Britain (Drudge was and remains a kind of curated rumour site, linking to other news sites, and mostly setting a news agenda via its creative use of headlines). The BBC's experience drew on its close watching of its American, corporate equivalents: its online editor, Mark Smartt, had visited CNN and ABC's nascent 


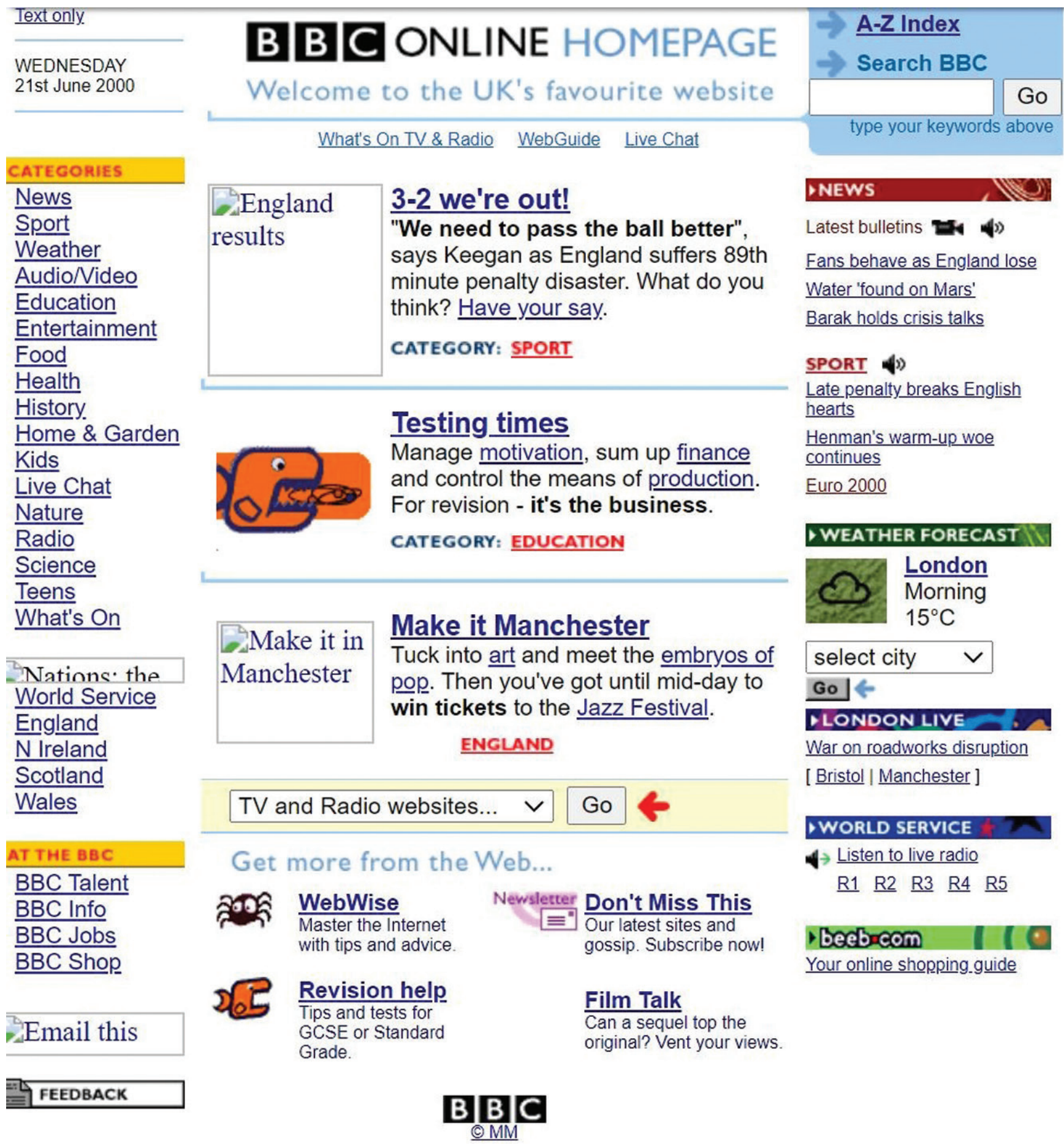

Figure 2. The home page of the popular BBC Online news site, from June 2000. The site featured the ability to listen live, online, to the World Service and other programmes. Source: Internet Archive, Wayback Machine. 
online operation. Smartt insisted on collaborative efforts with existing TV news staff, and an ethos of multi-skilled, digital-friendly journalism was set far sooner than in the United States. ${ }^{43}$

As the 2000s dawned, readership from the United States helped to well the numbers of people reading, listening, watching and otherwise consuming online journalism in the United Kingdom. Newspapers as diverse as the tabloid Daily Mail and the trade publication of record, the Press Gazette, transitioned to a more robust online presence. ${ }^{44}$

\section{News websites in the United States in the mid-1990s}

In the United States, online news, too, grew in popularity in similar fits and starts. Bruce Garrison, writing in 2005, noted that by the end of 1996, more than 800 news sites of some kind or another existed, with many of these static or secondary, but still established, and with 1,600 worldwide. 'Newspapers, more than any other medium, raced to go online during the mid-1990s,' spurred on, as Stuart Allan observed, by big news events, such as the 1995 Oklahoma City bombing, the second term of President Bill Clinton, with its various scandals, and the sad fate of Princess Diana, all of which fascinated Americans. ${ }^{45}$

But a much-smaller subgroup of news sites and their parent papers-early adopters-remained active and innovative. Publishers were worried about the still-niche market for the internet, and about competing with their print product. Looking back, this may seem foolish, but from their perspective, paper paid the bills, and internet users numbered, at most, in the hundreds of thousands, not yet the billions of the 21 st century.

Among others, The Washington Post, San Jose Mercury News, Boston Globe, New York Times, Chicago Tribune, Dallas Morning News, Los Angeles Times, Miami Herald, USA Today, and Wall Street Journal stood out, in Garrison's estimation. Whether because they were among the first to post original content online, like the Mercury News, which considered itself the authoritative journalistic voice for Silicon Valley, or broke scoops (news reported nowhere else), like the Morning News, or had committed corporate backing, like the Herald, an early paywall, like the Wall Street Journal, or, in the case of the Tribune, a partnership with a pioneering and popular graphical-user interface (GUI) and web provider such as America Online, these news organisations distinguished themselves early in the American context for taking risks and investing in an unproven technology. ${ }^{46}$ 
Friday, Jan. 10

Click for latest page update.

Find out by e-mail what's new this week.

NEED HELP?

Skim the Site Index. See the User Guide. Search the site.

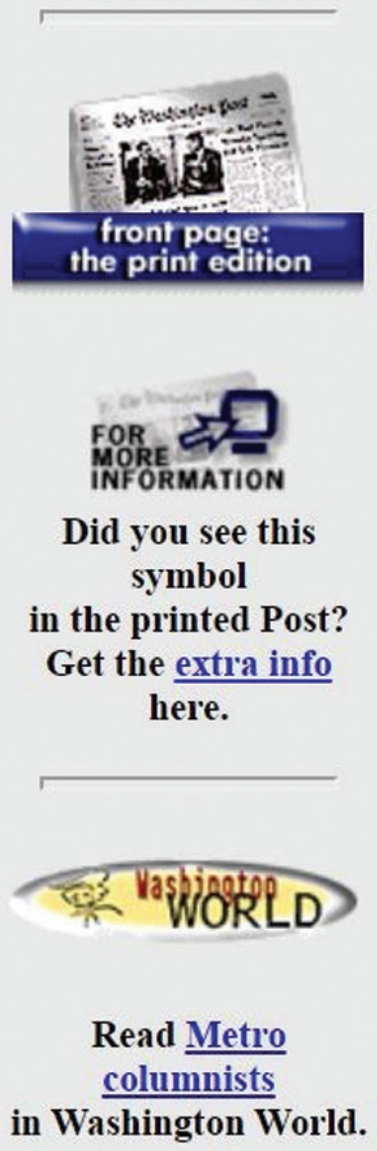

From Today's Post: the Weekend section.

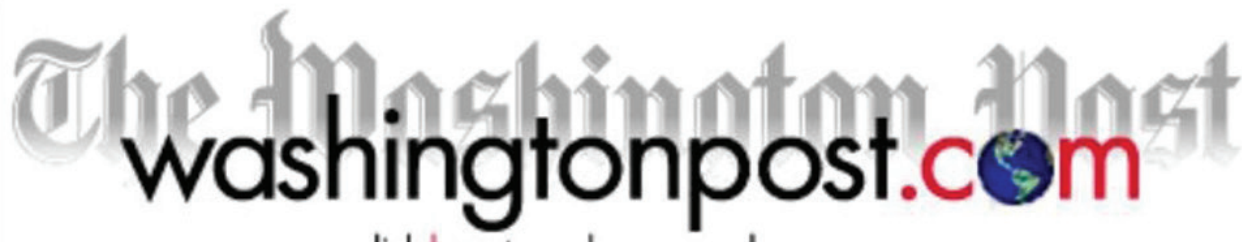

click here to make us your homepage

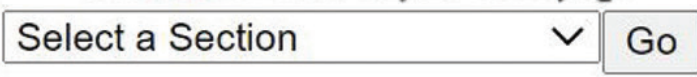

Today's Top News

Updated 7:11 a.m. EST

Gingrich Ethics Hearings Postponed The ethics case of House Speaker Newt Gingrich has once again been thrown into turmoil with the postponement of next week's public hearings.

\section{Gunshots Heard at Hostage Site}

For the second time in a week, gunshots have been heard at the diplomatic compound in Lima, Peru, where 74 hostages are being held.

\section{Die in Commuter Plane Crash}

A commuter plane trying to land in a snowstorm nose-dived into a field 18 miles short of the Detroit airport, killing all 29 people aboard.

\section{Today's Top News: Kolzig, Capitals Corral} Rangers, 2-0 ... Diplomat Will Be Recalled



Snowy Walk Washington area roadways are reported to be mostly clear today after Thursday's snow. Another light snowfall is expected tonight. (Post Photo by James A. Parcell) From The Post's Print Edition

\section{Mysterious Death Puts Spotlight on Child Pageants}

The mysterious death of 6-year-old JonBenet Ramsey in Boulder, Colo., has thrown a spotlight on the strange subculture of child beauty_pageants and whether it holds any clues in the child's death.

Only in the Web Edition 
Generally, though, then as now, the lack of a consistently successful business model eluded publishers. Following the broad British idea of trying for technical feasibility and audience first, and profit later, few of these sites dared to charge for their content, sometimes called the 'original sin' of online journalism, as referenced earlier. ${ }^{47} \mathrm{~A}$ variety of 'online news service models' were proposed, in the absence of a clear contender. These models included ${ }^{48}$ :

- 24-hours-a-day continuous news (such as CNN or later, Fox News)

- community bulletin board (essentially a static host site for forums)

- supplementary news site (special one-off sites covering events such as the 1996 Olympics)

- exclusive news site (focused on breaking news)

Other models projected that news sites might go more 'mainstream,' evolve into 'index and category,' 'meta and comment,' or 'share and discussion' formats, or assume some other, as-yet form undetermined. ${ }^{49}$ By the late 2000s, most newspapers would realise that they were losing far too much money, and having to invest far too many resources, in terms of sustainably maintaining profit margins, at least, to give away all their content all the time, and attempted paywalls, something the industry is still transitioning to today. Early paywalls mostly did not work, or at least not very well. Any massive shift away from advertising and (back) to subscribers was still some time away, and online news as an adjunct, or secondary medium, would define the era in the United States for most news organisations.

Nonetheless, tools such as news blogs, live interviews with experts, linking and the deployment of video and audio would, as in the United Kingdom, mean that newspapers were no slouches when it came to trying out storytelling on the internet. Challenges for the industry included the creation of reliable and relatively easy-to-use content-management systems, digital photography and, in the larger marketplace, the gradual replacement of 'dial up' internet with faster broadband. ${ }^{50}$ Journalists also faced deskilling, reskilling or at best, uneven workflows with digital tools, leading to a debate by the mid-2000s by both practitioners and scholars about the kinds of affordances that could be attributed to online-news tech, if any. ${ }^{51}$

Before all this, however, the overall feeling in the American journalism trade literature was one of optimism-news sites would lead to better reporting, a tighter bond with readers and a way to finally regain some of the breaking-news edge lost long ago to TV and radio news.

'Nobody sees the death of the ink and paper newspaper,' wrote Jack Lail in the winter 1994 issue of the Society of Professional Journalists' Quill. 


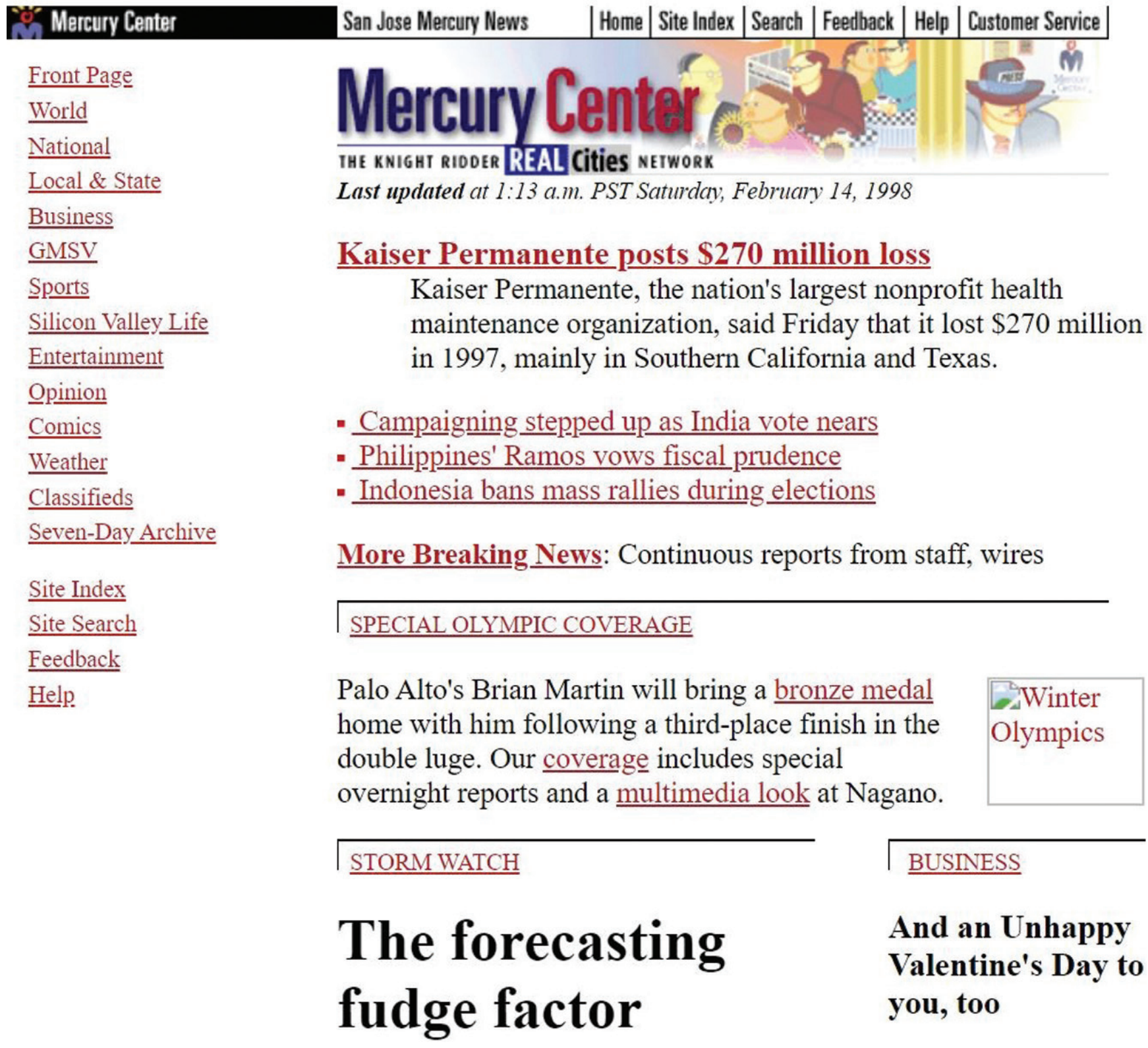

Figure 4. The news site of the San Jose Mercury News, Mercury Center, likely inspired other sites, both in the United States but also in the United Kingdom, with its web-first approach to posting news updates and in its connection to the print edition. Source: Internet Archive, Wayback Machine. 
Electronic newspapers can be painfully slow on services that charge by the minute [a common practice at the time]. Generally, they lack photos, graphics and video, and don't have the carry-it-anywhere portability of the good old newspaper. ${ }^{52}$

And yet, especially at field-leading newspapers such as the San Jose Mercury News, and its 'Mercury Center' (the name of its web-based edition, much like Guardian Unlimited), there was hope that readers would 'send letters to editors, join group chats with newspaper personalities, read classified ads, search its library, and discuss with each other everything from bike trails to foreign affairs. ${ }^{53}$ At 'Chicago Online,' the Chicago Tribune's online portal powered by AOL, users could buy tickets to see the Chicago Bulls or go to a concert. Still, management believed it was a kind of experiment and not a replacement for their primary product. ${ }^{54}$

This ideal of 'interactive newspapers' inspired a special section of the leading American trade journal on the news industry, Editor \& Publisher, in February 1995. But even in this early excitement, some voices expressed concern. At least one observer wrote that the difference between 1990 and 1995, with the commercial internet ascendant, was that 'the world has become a tangled web,' no longer just 'the Internet,' but a place where users expected a much richer, realtime experience than many newspapers had prepared for. With this 'Web/Mosaic environment [a reference to a popular early GUI], the hierarchy of information provision has been turned on its head,' with no need for an all-knowing, single source of news, wrote one observer. ${ }^{55}$ Others remained hopeful, that, in time, even-and perhaps especially-smaller newspapers could effectively launch and maintain attractive sites for their readers. ${ }^{56}$

At the end of the decade, with the proliferation of dedicated online news sites, a special issue of Columbia Journalism Review was still mostly full of optimistic projections about what the 2000s would bring to online news in the US. Frank Houston, a thoughtful analyst, reminded readers that the 'web,' i.e. the easier way of getting around on the internet, was still very, very young. He pointed to the launches of websites such as Slate and Salon, in 1996 and 1995, respectively, as indicative of the promise for niche sites for commentary on culture and technology, among other topics. ${ }^{57}$

After the terrorist attacks of September 11, 2001, the global felt need for better, faster, more in-depth online news would move decidedly from a novelty to a necessity, though the full story of that is beyond the scope of this short study..$^{58}$ 


\section{The end of the beginning: how the United States and United Kingdom experiences were similar ... and different}

Bob Franklin, a scholar based at Cardiff University’s School of Journalism, Media and Cultural Studies, noted that the era was marked by a sharp divide between those in favour of moving more news online, and those who wanted to invest more heavily in print.

'I remember being very struck at the time about how attitudes were incredibly manicheistic; those who favoured print were dinosaurs, those who favoured online (...) [had] no future (...) [since they] gave their news away for free [sic],' he recalled. ${ }^{59}$

Rusbridger notes this in his memoir, as well. Even as 9/11 and other seismic news events of the late 1990s and early 2000s demonstrated a hunger for trusted news organisations like newspapers to shift coverage to the internet, his colleagues-and even himself, at times-questioned the viability of doing so. Alongside these growing anxieties, though, the Guardian's Unlimited site, and its peers such as BBC Online, gained popularity.

'Many colleagues were binary-understandably suspicious,' he writes. 'If you loved digital then you must hate print, right? What was wrong with print? It still paid our wages-unlike digital pipe dreams. It had serendipity and portability-and generated cash. ${ }^{60} \mathrm{He}$ would explain that while he still adored print, and had spent his whole career up to that point primarily in that medium, that 'loving one didn't mean hating the other. In the end the choice would be out of our hands. ${ }^{61}$

These concerns, and a gradual, emergent strain of worry, appeared in the American trade press, as well. Jerry Ceppos, a retired Knight Ridder executive and the former dean of the Manship School of Mass Communication at Louisiana State University, recalled that his company, then among the larger newspaper chains in the world, was heavily invested in research and development with the internet. But it was hard-actually, nearly impossible, to see where things were going next, even at the end of the decade.

He recalled that the fate of classified-ad advertising, later consumed by the likes of Craigslist, but also job-hunting sites such as Monster.com or LinkedIn, worried his peers, keeping some literally awake at night. While it is too simplistic of a tale to lay the whole blame of the news industry's troubles at the fate of Craig Newmark, the founder of Craigslist, as other scholars and journalism observers have rightly demonstrated, it is just one example of the many unknowns faced by the newspaper world's leaders in the United States as well as the United Kingdom. ${ }^{62}$ 
Other observers from the end of this web 1.0 era were concerned and hopeful about what internet technologies could do with journalism. Journalists were no different than any other whitecollar occupational group of that era when it came to having mixed feelings.

'Reporters still go out on assignment and do investigative work, but they are more selective, especially since technology has added chores once done in composing rooms and control booths,' noted Michael Bugeja in Quill in May 2005. ${ }^{63}$

Bugeja, who at the time was the director of the Greenlee School of Journalism and Communication at Iowa State University, was worried that

the cumulative effect of greed, downsizing and computerization eventually may create an investigative void in a republic with a free press founded on the principle that truth, not profit, should rise to the top so that voters can make informed choices.

In some ways, though, Bugeja's more pessimistic strain remained in the minority. And it should be noted that in previous generations, reporters were discouraged from using telephones, for fear that doing so would keep them confined to their offices. ${ }^{64}$

Other more positive views from this era noted innovations such as the vertical news blog, with reporters posting their raw notes and files to their own personal or professional sites, with or without official blessing from their news organisations, but also the use of early streaming videos. In an ad from the spring 2000 issue of Columbia Journalism Review, for example, the Associated Press announced its partnership with Real Networks for 'AP Streaming News.'

'For news that words alone cannot deliver, AP brings you real-time sound and video of the day's top stories,' the ad promised, along with easy embedding on news sites. The idea behind streaming video was to provide cable-news production values with a deeper network of reports and experts. While not quite a dead end, it was not until most news consumers adopted faster internet connections a few years later that this kind of streaming news video became viable. ${ }^{65}$

\section{Conclusion}

When thinking about how parallel progress, however uneven, was made toward the launch of and early experimentation with online news in both the United Kingdom and the United States in the 
1990s, it is critical think about paths not taken, or the lost potential of joint projects. One wonders what would have become of more collaboration between, let us say, The Washington Post and The Guardian, or The Times of London and The New York Times, more than a decade before WikiLeaks. There were early experiments in the 2000s, but most did not go beyond informal proposals.

Granted, there were technical and cultural hurdles for any more pointed group efforts before, including the lack of high-speed internet adoption in both countries, and the more politicized (at least in the 1990s) nature of news in the United Kingdom. But even so, there were far more similarities, then as now, than differences, between the two nation's media systems. The potential for co-development was there, at least as revealed in the discourse in journalistic trade publications from this era. In the broader sense, and contrary to popular mythos, to reiterate, many news organisations were not caught off guard, overwhelmed or necessarily too slow to adopt to the internet. As this article has shown, many publishers in both the United Kingdom and the United States were indeed information-society pioneers, data-driven, overly cautious at times, perhaps, but aware of the big changes about to wash over the world due to the internet. They, in fact, led the way with vetted news online, long before Apple, Google, Facebook, Amazon and Microsoft became aware of, or concerned about, such things. There is a further danger of treating technology adoption as a kind of universal process, replacing the needed for case-based, granular histories. This has happened in media histories for pre-internet analogue computing machines and related technologies involving 'legacy systems. ${ }^{96}$ But by utilising a diffusions-of-innovations approach, and embracing, instead of pushing aside, the complexity of contingency, this study and others like it can contribute to a deeper appreciation of the messiness and uncertainty of particular historical moments. This kind of transitionary moment occurred in the 1990s with the emergence of news sites. It may be happening again with the rise of virtual reality and related tools for digital storytelling. But we may not know that for another generation. Let us hope that future media historians can take a similarly nuanced view of change in our own era. ${ }^{67}$

When looking at the 1990s and early 2000s, therefore, and at how national contexts impacted both the development of online news, but also how figures such as Rusbridger and Fidler encountered and influenced each other, it is fair to say that the adoption of the internet by news organisations was fraught, connected, and conditional. It was fraught, in being a moment full of promise but also one with largely unproven technologies and business models, connected, in being a time when companies were emerging from a post-Cold War context and thus with their global economic fates more interwoven than before, and conditional, in that media companies had the resources to invest in new technologies, but were cautious, reflexively, about what to do with those same resources. 
These contingent networks would lead, in time, to more formal collaborations, including story and resource sharing, with big stories such as political corruption and global pandemic. And it is these ties that may bring some hope for journalism as it continues to adopt to the economics of the online world. Arguably, the ongoing survival of journalism on both sides of the Atlantic is intrinsically linked, and has been so, since before the dawn of the internet age.

\section{Notes}

1. Cross-national research looks at two nations, and transnational research tends to examine two or more national contexts, but I will use the two terms fairly interchangeably here.

2. Ruth Addicott, “Magazines Back on Track After Net Panic,” Press Gazette, May 3, 2001; https://www. pressgazette.co.uk/magazines-back-on-track-after-net-panic/.

3. See, for example, Jeremy Tunstall, The Media Were American: US Mass Media in Decline. Second Edition (New York: Oxford University Press, 2007).

4. Ethan Zuckerman, “The Internet's Original Sin It's Not Too Late to Ditch the Ad-based Business Model and Build a Better wWeb,” The Atlantic, Aug. 14, 2014; https://www.theatlantic.com/technology/ archive/2014/08/advertising-is-the-internets-original-sin/376041/.

5. Paul Williams, The Computerized Newspaper: A Practical Guide for Systems Users (Oxford: Heinemann Professional Publishing Ltd., 1990), 15, 283.

6. Ibid., 285.

7. Will Mari, A Short History of Disruptive Journalism Technologies (Abingdon, UK: Routledge, 2019).

8. Williams, Computerized Newspaper, 287.

9. Mar Hicks, Programmed Inequality: How Britain Discarded Women Technologists and Lost Its Edge in Computing. (Cambridge, Mass.: MIT Press, 2017).

10. Mari, A Short History of Disruptive Journalism Technologies.

11. Julien Mailland, and Kevin Driscoll. Minitel: Welcome to the Internet (Cambridge, Mass.: MIT Press, 2017).

12. David Carlson, "The History of Online Journalism," 31-55, in Digital Journalism: Emerging Media and the Changing Horizons of Journalism, ed. Kevin Kawamoto (Lanham, Md.: Rowan \& Littlefield, 2003).

13. Kevin Driscoll, Hobbyist Inter-networking and the Popular Internet Imaginary: Forgotten Histories of Networked Personal Computing, 1978-1998. Ph.D. dissertation (University of Southern California, 2015). 
14. For a collection of oral histories from this era, see Michael Shapiro, Anna Hiatt, and Mike Hoyt, Tales from the Great Disruption: Insights and Lessons from Journalism's Technological Transformation (Minneapolis, Minnesota: Big Roundtable Books, 2015).

15. Valerie Belair-Gagnon and Allison J. Steinke, “Capturing Digital News Innovation Research in Organizations, 1990-2018," Journalism Studies 21, no. 12 (2020): 1724-1743. They conclude that while perhaps underutilised, a diffusions-of-innovation approach has a rich legacy in journalism studies and encourage a historical grounding for its (and other theoretical) application(s), following the work of Margaret H. DeFleur and Lucinda D. Davenport; see their, "Innovation Lag: Computer-Assisted Classrooms vs. Newsrooms," The Journalism Educator 48, no. 2 (1993): 26-36.

16. Everett Rogers, Diffusion of Innovations, Fourth Edition (New York: Free Press, 1995); Eric Schatzberg, “Where Do Models of Innovation Come From? Benoit Godin, Models of Innovation,” Technology and Culture 61, no. 1 (2020): 337-340; Benoit Godin, Models of Innovation: The History of an Idea (Cambridge, Mass.: MIT Press, 2017).

17. See Wayne W. LaMorte, “Diffusion of Innovation Theory,” Behavioral Change Models, Boston University School of Public Health, https://sphweb.bumc.bu.edu/otlt/mph-modules/sb/behavioralchangetheories/ behavioralchangetheories4.html, accessed March 10, 2021; see also, Leif Singer, “On the Diffusion of Innovations: How New Ideas Spread,” https://leif.me/on-the-diffusion-of-innovations-how-new-ideasspread/, accessed March 10, 2021.

18. Schatzberg, "Where Do Models of Innovation Come From?” 339; Schatzberg gives Rupert Maclaurin credit for actually originating much of what would become the 'linear model' of adoption.

19. Ángel Arrese, "From Gratis to Paywalls: A Brief History of a Retro-innovation in the Press's Business," Journalism Studies 17, no. 8 (2016): 1051-1067.

20. Arrese, "From Gratis to Paywalls," 1052-53.

21. Steen Steensen, "WHAT’S STOPPING THEM? Towards a Grounded Theory of Innovation in Online Journalism," Journalism Studies 10, no. 6 (2009): 821-836.

22. Pablo Boczkowski, Digitizing the News: Innovation in Online Newspapers (Cambridge, Mass.: MIT Press, 2004); Steensen, WHAT’S STOPPING THEM?" 824-825.

23. Steensen, WHAT’S STOPPING THEM?” 832-833.

24. Megan Sapnar Ankerson, Dot-Com Design: The Rise of a Usable, Social, Commercial Web (New York University Press, 2018); Jessa, Lingel, An Internet for the People: The Politics and Promise of Craigslist (Princeton University Press, 2020). 
25. Niels Brügger, The Archived Web: Doing History in the Digital Age (Cambridge, Mass.: MIT Press, 2018); Ian, Milligan, History in the Age of Abundance?: How the Web is Transforming Historical Research (Montreal, Canada: McGill-Queen’s University Press, 2019).

26. On the positive side, the necessity to rely on alternative sources led, for example, to a couple of key interviews with people working in the field during this era, who helpfully filled in some knowledge gaps on the United Kingdom side. But not being able to use interlibrary loan services was a particularly challenging problem, as specific issues requested were sometimes thus not available.

27. For a full list of both primary and secondary sources, please see below.

28. In the latter case, to be clear, this was done in order to reinforce the lack of access to trade publications from the United Kingdom during the time period examined.

29. Boyles, Jan Lauren, and Jared Meisinger. "Automation and Adaptation: Reshaping Journalistic Labor in the Newsroom Library," Convergence: The International Journal of Research into New Media Technologies. 26 no. 1 (2018): 178-192.

30. Hall, Jim. Online Journalism: A Critical Primer (London: Pluto Press, 2001), 3.

31. Alan Rusbridger, Breaking News: The Remaking of Journalism and Why it Matters Now (New York: Picador, 2017), 24. Some scholars, including Christine Ogan and Randy Beam, have a modest estimate of these sites, probably more 'truly' dedicated to hosting news content, with as few as a few dozen, about 60, and no more than about 500. In any case, throughout the 1990s, the number of newspaper web sites on both sides of the Atlantic would grow substantiality. The quality of the sites, of course, would vary, from a static web page for a smaller newspaper to a dedicated, separate operation like that used for The Guardian or The San Jose Mercury News and the latter's Mercury Center. For more on Mercury Center, see Michael Shapiro's oral history, “The Newspaper That Almost Seized the Future,” The Columbia Journalism Review, November/December 2011; https://archives.cjr.org/feature/the_newspaper_that_almost_seized_the_future.php; see also, Christine Ogan and Randy Beam, "Internet Challenges for Media Businesses," 279-314, in The Internet and American Business, ed. William Aspray and Paul Ceruzzi (Cambridge, Mass.: MIT Press, 2008).

32. Arrese, "From Gratis to Paywalls." Arrese, in turn, draws from Chip Brown, "State of the American newspaper. Fear.com," American Journalism Review 20, no. 10 (1999): 50-71.

33. Rusbridger, Breaking News, 28-29.

34. Ibid., 47.

35. Ibid., 58-61.

36. Ibid., 73. 
37. Ibid., 57, 64-5.

38. Ibid., 65 .

39. This is a paraphrase of a colleague of Preston's who witnessed his plenary speech at the inaugural Future of Newspapers conference in Cardiff, UK, and had informal conversations with Preston while there. The colleague wished to remain anonymous for this project. For more on Preston, see: McKie, David, "Peter Preston Obituary: Guardian Editor Who During 20 Years in the Role Played a Decisive Part in Shaping the Paper's Future," The Guardian, Jan. 7, 2018; https://www.theguardian.com/media/2018/jan/07/peter-preston-obituary

40. “Shovelware,” PCMag Encyclopedia, PC Magazine, https://www.pcmag.com/encyclopedia/term/shovelware, accessed March 11, 2021.

41. Stuart Allan, Online News: Journalism and the Internet (Berkshire, UK: Open University Press, 2005), 35.

42. Ibid., 36-37.

43. Ibid., 37-38.

44. William Turvill, “Piers Morgan 'Resigns' and Six-strong Team Launches Website for Daily Mail: Ten Years Ago This Week," Press Gazette, May 14, 2014; https://www.pressgazette.co.uk/piers-morgan-resigns-andsix-strong-team-launches-website-for-daily-mail-ten-years-ago-this-week/; Press Gazette staff, “Our New Website: Cleaner, Quicker and Easier to Use,” Press Gazette, May 21, 2007; https:/www.pressgazette.co.uk/ our-new-website-cleaner-quicker-and-easier-to-use/

45. Bruce Garrison, “Online Newspapers,” 3-46, 6, in Online News and the Public, ed. Michael B. Salwen, et al. (Mahweh, New Jersey, Lawrence Erlbaum Associations, Publishers, 2005); Allan, Online News, 2005.

46. Garrison, “Online Newspapers,” 20-41.

47. Rusbridger, Breaking News, 76; Rusbridger credits media-economics expert Alan Mutter with explicating this phrase; see Ryan Chittum, “Audit Interview: Alan D. Mutter," Columbia Journalism Review, Jan. 23, 2009; https://archives.cjr.org/the_audit/audit_interview_alan_d_mutter_1.php

48. Garrison, “Online Newspapers,” 15-17.

49. Mark Deuze, “Online Journalism: Modeling the First Generation of New Media on the World Wide Web. First Monday. Nov. 17, 2003; https://firstmonday.org/article/view/893/802.

50. Juliette De Maeyer. “Content Management Systems and Journalism,” Oxford Research Encyclopedia of Communication, 25 Jun. 2019; https://oxfordre.com/communication/view/10.1093/ acrefore/9780190228613.001.0001/acrefore-9780190228613-e-792.

51. Henrik Örnebring, “Technology and Journalism-as-labor: Historical pPerspectives,” Journalism 11, no. 57 (2010).

52. Jack Lail, “Newspapers On-line: Electronic Delivery Is Hot ... Again,” Quill, Jan.-Feb. 1994, 39. 
53. Ibid., 40.

54. Ibid., 41.

55. Michael Conniff, “A Tangled Web for Newspapers,” Editor \& Publisher, Feb. 4, 1995, 4-5.

56. Jack Dale, "Real Life Implementation of an Online Newspaper Presence," Editor \& Publisher, Feb. 4, 1995, 22-24.

57. Frank Houston, “Enjoy the Ride While It Lasts,” Columbia Journalism Review, July-August 2000, 22-25.

58. To that end, the author is working on a longer, book-length study of the impact of internet on the news industries in the United States, United Kingdom and Canada, from about 1992-2008.

59. Interview with author, June 10, 2020; an affordance is 'the type of action or a characteristic of actions that a technology enables through its design.' See Jennifer Earl and Katrina Kimport, Digitally Enabled Social Change: Activism in the Internet Age (Cambridge, Mass: MIT Press, 2011), 10.

60. Rusbridger, 74 .

61. Ibid., 74 .

62. Interview with author, June 10, 2020; Ceppos was interviewed as he was a key eyewitness to high-level discussions within Knight Ridder, especially at The San Jose Mercury News, where he was managing editor, eventually its executive editor, and responsible for some of the c. 1995-era success of the paper's online news presence, the Mercury Center; see also Shapiro, “The Newspaper That Almost Seized the Future,” 63, but also, Jack Shafer, “Don’t Blame Craigslist for the Decline of Newspapers: It’s Fun to Beat Up on Craig Newmark For the End of Classifieds, But Papers Were Greedy, Too," Politico, Dec. 13, 2016; https://www. politico.com/magazine/story/2016/12/craigslist-newspapers-decline-classifieds-214525 and David Streitfeld, “Craig Newmark, Newspaper Villain, Is Working to Save Journalism,” The New York Times, Oct. 17, 2018; https://www.nytimes.com/2018/10/17/technology/craig-newmark-journalism-gifts.html.

63. Michael Bugeja, “Computers Keep Reporters in the Office, Off Their Beats,” The Quill, May 2, 2005; https:// www.quillmag.com/2005/05/02/computers-keep-reporters-in-the-office-off-their-beats/.

64. Will Mari, "Technology in the Newsroom: Adoption of the Telephone and the Radio Car from c. 1920 to 1960," Journalism Studies 19, no. 9 (2018), 1366-1389.

65. Associated Press and RealNetworks, "AP Streaming News with RealNetworks," Columbia Journalism Review, March-April 2000, 1.

66. Christopher Leslie, “As We Could Have Thought: Deploying Historical Narratives of the Memex in Support of Innovation,” Technology and Culture 61, no. 2 (2020): 480-511; Michael Stevenson and Anne Helmond, “Legacy Systems: Internet Histories of the Abandoned, Discontinued and Forgotten," Internet Histories, 4, no. 1 (2020): 1-5.

67. To that end, I would recommend the work of David Karpf and Jessa Lingel. 


\section{Biography}

Will Mari is assistant professor of media history and media law at Louisiana State University's Manship School of Mass Communication. He studies the history of newsroom culture and also examines analogue-to-digital transitions and the disruption of technology tools over time on journalistic work practices.

\section{TMG Journal for Media History}

Volume 24 No $(1 / 2) / 2021$

DOI

https://dx.doi.org/10.18146/tmg.784

PUBLISHER

Netherlands Institute for Sound and Vision

\section{COPYRIGHT}

Each article is copyrighted (c) by its author(s) and is published under license from the author(s). When a paper is accepted for publication, authors will be requested to agree with the Creative Commons Attribution 4.0 International License. 